\title{
Synoptic and dynamical analyses of ENSO extreme events over Australia
}

\author{
$\underline{\text { J.A. Whelan }}^{a}$, J.S. Frederiksen ${ }^{a}$, C.S. Frederiksen ${ }^{, b}$ and S.L. Osbrough ${ }^{a}$ \\ ${ }^{a}$ CSIRO Marine and Atmospheric Research, Centre for Australian Weather and Climate Research \\ (CAWCR), Aspendale, VIC, Australia \\ ${ }^{b}$ CAWCR, Bureau of Meteorology, Melbourne, VIC, Australia \\ Email: jennifer.whelan@,csiro.au
}

\begin{abstract}
The El Niño Southern Oscillation (ENSO) plays a major role in the variability of Australia's climate. Periodic droughts and wet conditions follow the ENSO phases. Understanding ENSO and its effects on Australia is never more important than in the cases of extreme events such as severe droughts or flooding. In this paper, we examine changes in the basic climate state over Australia during the two extreme flooding periods of January 1974 and January 2011. 1973-1976 and 2010-2012 are considered the two most severe La Niña periods in terms of precipitation and flooding in Australia since 1900. The largest floods occurred during January 1974 and late December 2010 through January 2011, in both cases flooding the Queensland and New South Wales coastal areas, and in the latter case causing floods inland and south down to Victoria.
\end{abstract}

We employ complementary avenues of analysis, looking at both the synoptics and atmospheric dynamics of the southern hemisphere climate during these events. Synoptically, the circulation over Australia often changes significantly during La Niña phases. In strong La Niña periods, often there are persistent low pressure systems over Australia during flooding periods, replacing or displacing the typical high pressure system seen in neutral or El Niño conditions. In 2011, higher sea surface temperatures (SSTs) in the western Pacific, due to an unusually strong negative Indian Ocean Dipole (IOD), caused lower pressure over the Indian Ocean, Australia, Indonesia and the western Pacific and above-average amounts of atmospheric moisture. These low pressure systems persisted over Australia with the aid of blocking high pressure systems in the Tasman Sea and easterly onshore winds. These events, coupled with anomalously strong westerly winds bringing down the large amounts of monsoonal tropical moisture, led to intense flooding. January 1974 was a similar case, albeit with a weaker negative IOD and smaller SST anomalies. To distinguish the classes of disturbances active during these events, their initial growth, growth rates, and interactions, we examine the leading dynamical modes in both cases.

Dynamical modes associated with these flooding events are determined using a primitive equation instability model. We find that heavy rainfall is associated with increased growth rates of Kelvin waves, intraseasonal oscillations (ISO), monsoon disturbances, and associated blocking over the Tasman Sea, as well as some changes in the extratropical storm track modes. In particular, we find that the Kelvin wave grows explosively and is strongly convectively coupled in the Australian monsoonal region, enhancing convection over Australia. In addition, intraseasonal oscillations grow strongly in the Australian region and contribute to the convection and rainfall, at the same time. We find similar Kelvin waves and monsoonal modes in both events, although in 1974 both were slightly stronger than in 2011. Our dynamical analyses agree with the synoptic observations and provide a more complete description of the reasons for the severity of both events.

It appears necessary for several factors to be both present and timed accordingly for flooding impacts to be maximal. In both 1974 and 2011, active monsoonal modes and intraseasonal oscillations met unusually rapidly growing Kelvin waves. In 2011, a strongly negative IOD with high SSTs made more moisture available. Understanding the nature of these extreme events over Australia is a fundamental step in the pursuit of accurate predictions of future ENSO impacts, Australia's future climate and climate extremes, and water resources planning.

Keywords: El Niño Southern Oscillation, extreme events, La Niña, monsoon, Kelvin wave 


\section{INTRODUCTION}

The El Niño Southern Oscillation (ENSO) is a coupled ocean-atmosphere phenomenon that causes major shifts in regional weather patterns on seasonal to multi-year time scales (e.g., Philander, 1990). During La Niña phases, stronger trade winds move warmer water, and the center of convection, westward toward Australia. Australia is particularly vulnerable to ENSO (McBride and Nicholls, 1983; Nicholls et al., 1997; Wang and Hendon, 2007). The country typically sees drier conditions during El Niño phases, and higher than average rainfall during La Niña phases (McBride and Nicholls, 1983). According to the Australian Bureau of Meteorology (http://www.bom.gov.au/climate/enso), the La Niñas of 1973-1976 and 2010-2012, and their most significant flooding during January 1974 and 2011, were two of the most widespread flood events over Australia since 1900. While ENSO metrics such as Southern Oscillation Index (SOI, difference in sea level pressure between Darwin and Tahiti) indicate severity of ENSO conditions - extreme SOIs of 27 and 28 preceded the 1974 and 2011 floods - metrics do not necessarily indicate the extent of impact (Wang and Hendon, 2007). Nor do they offer an understanding of the dynamical conditions causing the widespread impact seen in both periods.

There has been extensive research on ENSO going back decades, but less work has been done on the causes of circulation features associated with La Niña phases in the southern hemisphere (SH) or Australia specifically. Karoly (1989) described general SH circulation features during El Niño conditions. Others have looked at the relationship between ENSO and the Southern Annular Mode (SAM) and Antarctic sea ice extent in the SH (e.g., L'Hereux and Thompson, 2006; Pezza et al., 2008). Most of the wide range of research looking at the Madden Julian Oscillation (MJO) and ENSO focuses on the MJO contribution to El Nino conditions (Hendon et al. 2007, Moon et al. 2011), although Wheeler et al. (2009) showed that MJO was a main driver of rainfall in northern Australia and could also influence rain in the extratropics over the austral summer. The IOD is known to have a relationship with Australian rainfall (Ashok et al. 2003, Meyers et al. 2007). Risbey et al (2009) considered ENSO, IOD, MJO, SAM and blocking as drivers of Australian rainfall, all having seasonal and geographically-varying influences. Brown et al. (2009) showed that precipitation impacts of El Niño phases were modulated by the number and behaviour of cutoff low pressure systems over Australia. The type of El Niño (or La Niña) also affects the extent of the negative (positive) precipitation anomaly (Wang and Hendon 2007; Taschetto and England 2009; Cai and Cowan 2009).

Frederiksen and Frederiksen $(2005,2007)$ have previously looked at dynamical modes in terms of climate regime change and shift of storm tracks to explain the significant rainfall reduction in southwest western Australia. Frederiksen and Frederiksen (2011) also studied the causes of the southern Australian drought of 1997-2006 (extending to 2009), associated with some medium to strong El Niño events, in terms of changes in dynamical modes. As yet no such studies have been performed for La Niña conditions. In this paper, we apply this method of analysis to the periods of January 1974 and January 2011, which together with synoptic descriptions, offers a more complete explanation and case study of the reasons behind the extensive precipitation impacts of the two most severe flooding events in Australia's recent history.

\section{SYNOPTIC DESCRIPTION OF LA NIÑA EXTREME PRECIPITATION EVENTS}

\subsection{January 1974}

1973 was Australia's 3rd wettest year, 1975 the 5th wettest, and 1974 is still the wettest year on record, according to the Australian Bureau of Meteorology. In particular, Australia experienced the heaviest flooding in its recorded history during January 1974. Some areas received more than twice their average annual rainfall in one month. One catchment near Brisbane received $1300 \mathrm{~mm}$ in five days. Inland areas remained submerged for weeks and in some areas months.

In October and November 1973, a westerly anomalous flow built over the Indian Ocean along the equator. It then gained strength over Indonesia in December, still following a westerly path along the equator. The trade winds, which run directly into this flow, weakened below the equator from October to December west of 180E. A weak anticyclonic motion developed around the high over Australia, drawing from the strong midlatitude westerlies over the south of Australia, in November and December. By January, however, the tropical westerly winds had gained considerable strength and at $140 \mathrm{E}$, they extended to $10 \mathrm{~S}$ from the equator, following the low-pressure ridge along the north and east coasts. These winds displaced the anticyclonic motion around the high: it moved from the northern half of Australia to the southern half, and the midlatitude westerlies only covered Tasmania. The cyclonic motion around the low over the northern half of Australia, and the anticyclonic motion around the high over the southern half, converged off the east coast to 
create an area of confluence and unstable easterly winds across Australia. Both these, plus blocking highs in the Tasman Sea, served to trap the convection over Australia and prevent its moving off into the Pacific. A weakly negative IOD paired with already-warmer SSTs in the Indian Ocean and tropical Pacific made available more atmospheric moisture.

\subsection{January 2011}

Second only to the 1973-1976 period in precipitation totals is 2010-2012. From 2010 to the end of 2011, area-averaged rainfall totals over Australia were $1402 \mathrm{~mm}$, very near the area-averaged $1407 \mathrm{~mm}$ total for 1973-1974. The strong La Niña of 2010-2011 decayed in autumn and receded May - Sept 2011. A second, weaker La Niña developed in spring, and by the end of 2011, rainfall was above average over two-thirds of Australia.

However, the most extreme flooding occurred in late December 2010 to January 2011. Low pressure troughs over Australia and a chain of blocking high pressure systems in the Tasman Sea caused northerly winds and easterly flow near coasts. A strongly negative Indian Ocean Dipole, which decayed only in November, with unusually high SSTs around Australia, led to more convection (not shown). From December 23-28, 2010 moist easterly flow and cyclone Tasha resulted in a number of Queensland stations setting all-time daily records, some reaching up to $273 \mathrm{~mm}$. By January 10, the tropical moisture had reached southeast Queensland and northeast New South Wales with daily precipitation totals reaching $298 \mathrm{~mm}$ at one station in southern Queensland. Meanwhile, the tropical moisture and northeasterly flow was drawn down into a slow-moving trough over Victoria, bringing very humid conditions seen only once before in Melbourne. The low pressure system persisted due in part to the blocking high pressure systems south of Tasmania, and Victoria received its entire summer's average rainfall in the six days of January 9-14 (Bureau of Meteorology, website).
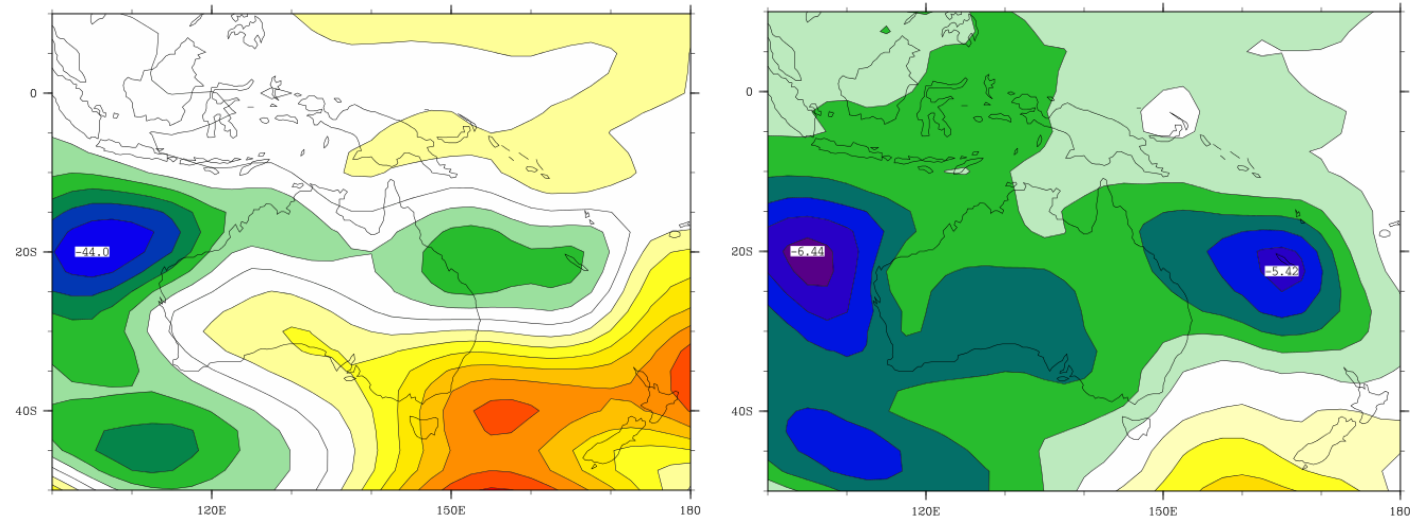

Figure 1. $700 \mathrm{hPa}$ geopotential height anomaly $(\mathrm{m})$ (left) and sea level pressure (mb) (right) anomaly in January 2011 from 1949-2009 January averages. Contour intervals (CI) are 5m (left) and 1mb (right). (Data from NCEP reanalysis (Kalnay et al.,1996)).

\subsection{Circulation over Australia during La Niña}

In neutral and El Niño conditions, there is higher pressure throughout the Indian Ocean, Australia and the western Pacific than in La Niña years. Typically, a high can be seen at $700 \mathrm{mb}$ over the Indian Ocean that extends east over western and central Australia, driving winds in an anticyclonic pattern from the Indian Ocean eastward across the south Australian coast, curving around northward to create an easterly flow across the northern half of Australia (not shown). During La Niña conditions, however, this high over Australia is usually either smaller or nonexistent; in 1974, there was a large low pressure system over Australia. In 2011 (Figure 1), there are negative pressure anomalies over the Indian Ocean and Australia.

Without the usual strength of the anticyclonic flow around the high, tropical westerly winds originating in the Indian Ocean and extending through Indonesia are drawn down from the equator into northern and eastern Australia towards the areas of lower pressure, bringing with them large amounts of tropical moisture. Figure 2 shows these differences in the $700 \mathrm{hPa}$ zonal wind. These tropical westerly winds do not seem to build during neutral or El Niño years, staying at 3-4m/s. They grew to 10m/s during the La Niña year of 1974. Likewise, they were anomalously strong in 2011. These winds build during most La Niña periods, but do not always take the same path. In the La Niña year of 2008, the winds were drawn out to the low over the western Pacific. The 1999 La Niña had the typical lower pressure over the Indian and Pacific Oceans but 
there was a strong enough high over Australia that likely blocked the tropical westerly winds from dropping down over Australia.

Although the wind pattern is similar during all years -- flowing from the Indian Ocean through Indonesia, combining with the northerly winds of the Indonesian Flow Through to curve down towards Australia -- their effect on Australia is minimized during El Niño years because the winds are weaker and move more towards the western Pacific due to the strong anticyclonic high over Australia. During La Niña years, a series of blocking highs in the Tasman Sea may exacerbate the tropical flow's impact on Australia with anticyclonic south/easterly winds keeping the systems over land for longer. Next, we examine the dynamical modes associated with the January 2011 and 1974 La Niña events.

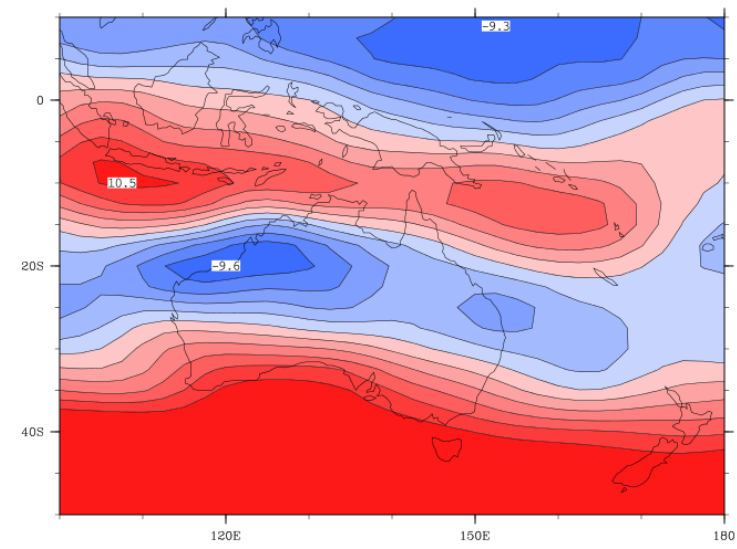

Figure 2. $700 \mathrm{hPa}$ zonal wind differences between January 2011 and 1949-2009 January average. CI is $2 \mathrm{~m} / \mathrm{s}$. (Data from NCEP reanalysis (Kalnay et al. 1996) ).

\section{PRIMITIVE EQUATION INSTABILITY MODEL}

The dynamical modes described in this article have been derived based on a two-level linearized primitive equation model that was developed and applied in a series of studies by Frederiksen and Frederiksen (2005, 2007, 2011). The model employs a Kuo-type cumulus heating parameterization with closures for convection and evaporation-wind feedback (Frederiksen 2002). The basic state and perturbation fields of the model are expanded in spherical harmonics with the perturbation fields having a time dependence $\exp (-i \omega t)$. Here $t$ is time, $\omega=\omega_{r}+i \omega_{i}$ is the complex angular frequency, $\omega_{r}$ is the frequency, $\omega_{i}$ is the growth rate, $T=2 \pi / \omega_{r}$ the period and $\tau=\omega_{i}^{-1}$ the e-folding time. We use the same horizontal resolution as in the study of Frederiksen et al. (2011) corresponding to a so-called rhomboidal 15 resolution in which the zonal wavenumber $m$ ranges from -15 to +15 and the total wavenumber $n$ ranges from $|m|$ to $|m|+15$ in the spherical harmonics expansion. We use the same standard parameters for the strength of the convection, evaporation and dissipation as in Frederiksen and Frederiksen $(2005,2011)$ and Frederiksen et al. (2010, 2011). The basic states that we focus on here are for January 2011 and 1974 that were times of major La Niña events as discussed above.

\section{DYNAMICAL MODES ASSOCIATED WITH LA NIÑA DURING JANUARY 2011}

Storm track modes are usually the fastest growing instability modes, although larger scale modes reach larger amplitudes in nonlinear integrations (Frederiksen, 1981). The fastest growing SH storm track mode is mode 3 with a period of $T=1.7$ days and an e-folding time of $\tau=2.1$ days. It has a disturbance stream function (not shown) very similar to that of mode 1 for 1949-1968, shown in Figure 1 (top panel) of Frederiksen et al. (2011) with significant amplitude across south-eastern Australia. This is in contrast to mode 1 for 1997-2006 shown in the bottom panel of that same figure. During 1997-2006, extending to 2009, southern Australia experienced an extensive drought, partly associated with medium to strong El Niño events. With the January
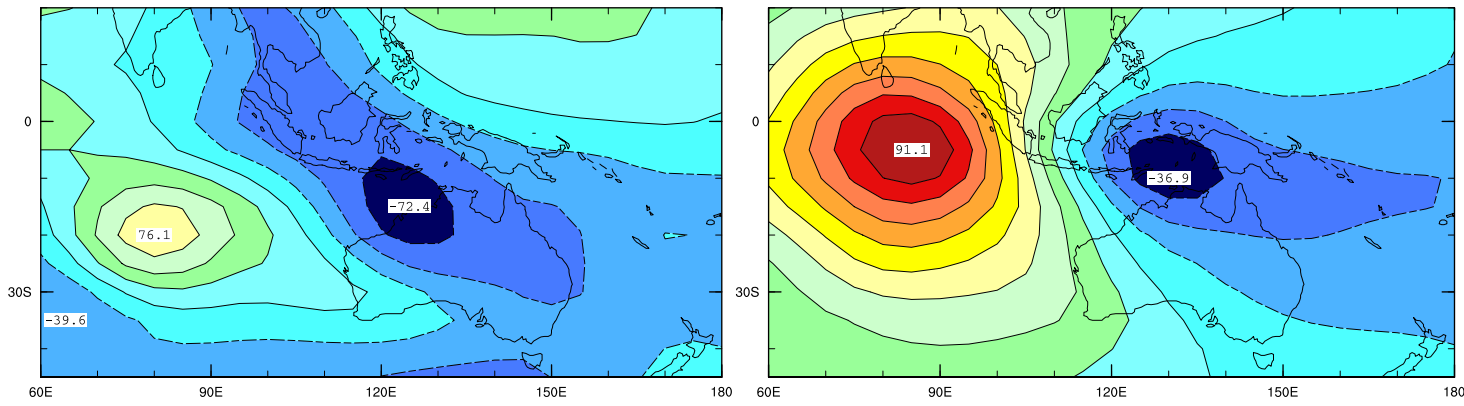

Figure 3. $300 \mathrm{hPa}$ streamfunction (left) and velocity potential (right) of the Kelvin wave, with a 4.2 day e-folding time and period of 18 days, during January 2011. Both are dimensionless quantities. CIs are 20 (left) and 10 (right). 
2011 La Niña, the storm tracks have returned to cross southeastern Australia; this is the case not just for the leading SH storm track mode but also for many of the slow-growing cyclogenesis modes (not shown).

La Niña, during January 2011, was also associated with the explosive growth of Kelvin waves with the leading disturbance having a period $T=18.4$ days and an e-folding time of $\tau=4.2$ days which is roughly three times shorter than for the leading Kelvin wave for the January 1979 basic state studied by Frederiksen (2002) (More information on Kelvin waves can also be found in that paper). Figure 3 shows the $300 \mathrm{hPa}$ streamfunction and velocity potential associated with the leading January 2011 Kelvin wave. At the phase shown in Figure 3, there is a large negative streamfunction anomaly centered over northern Australia as well as a negative velocity potential anomaly associated with large scale uplift and precipitation.
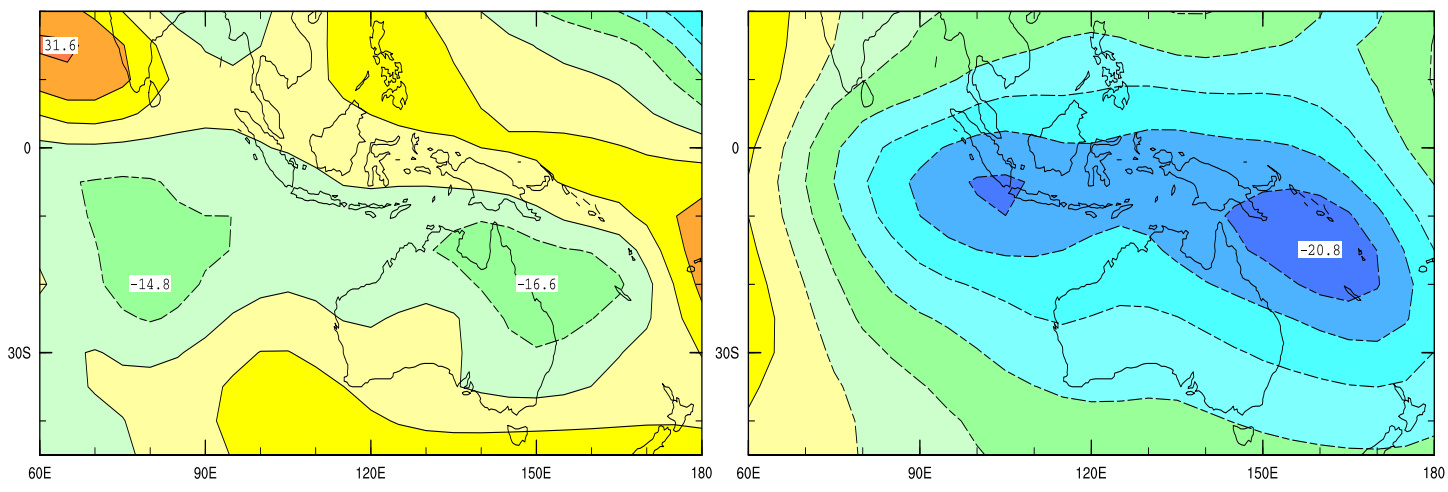

Figure 4. $300 \mathrm{hPa}$ streamfunction (left) and velocity potential (right) of the leading ISO. CI: 10, 3.

There is also a group of fast growing intraseasonal oscillation (ISO) modes, with periods between 40 and 50 days and e-folding times between 5.8 and 6.8 days, associated with the La Niña during January 2011. The fastest growing of this group is mode 46 with a period of $T=47.7$ days and an e-folding time of $\tau=5.8$ days. Figure 4 shows the $300 \mathrm{hPa}$ streamfunction and velocity potential of this leading ISO; at the phase depicted it has a negative streamfunction anomaly and negative velocity potential in a band stretching from northeastern Australia to between $60^{\circ}$ and $90^{\circ} \mathrm{E}$. The flow fields of the intraseasonal oscillation modes in Figure 4 are again consistent with the anomalous precipitation across northern Australia during January 2011.
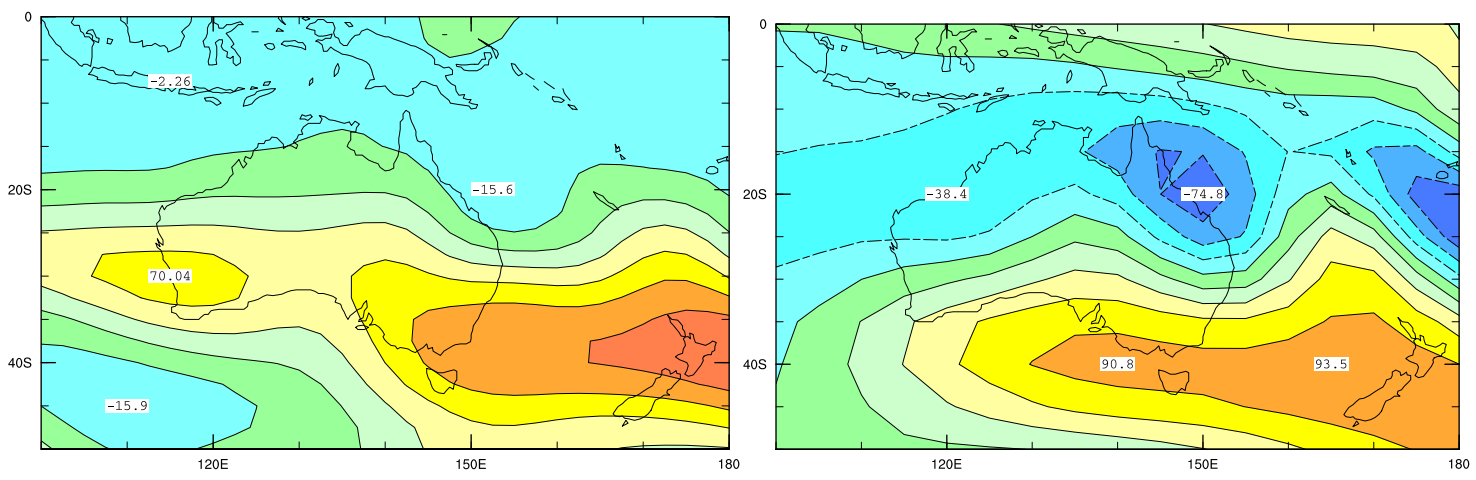

Figure 5. (left) 300hPa geopotential height differences between January 2011 and January's 1949-2009.

(right) Streamfunction of mode 47, one of the three leading monsoonal modes in January 2011. We have plotted the inverse of the streamfunction in the SH to show the similarities. CI: $20 \mathrm{~m}, 20$.

We also found that there are fast growing quasi-stationary disturbances associated with the monsoon circulation over Australia, similar to those discussed by Frederiksen and Frederiksen (1993,1997), but of somewhat larger scale and with streamfunctions that have opposite signs over Australia and to the south and over the Tasman Sea. The leading monsoon disturbances are mode 47 with a period of $T=\infty$ and an efolding time of $\tau=5.8$ days, mode 54 with period of $T=\infty$ and e-folding time of $\tau=6.6$, and mode 73 with a period of $T=183$ days and an e-folding time of $\tau=8.0$ days. Circulation features associated with the stationary monsoon mode 47 are shown in Figure 5 (right), which depicts the $300 \mathrm{hPa}$ streamfunction. Figure 5 (left) shows the difference between the $300 \mathrm{hPa}$ geopotential height in January 2011 and the average January for 1949 to 2009. We note that, apart from scales, the plots in Figure 5 are broadly similar, 
suggesting that the monsoon mode captures the instability characteristics of the anomalous circulation over northern Australia during January 2011. We also note high pressure systems to the south and southeast of the low over northern Australia, including over the Tasman Sea, that are associated with blocking. These modes again reflect the anomalous precipitation over northern Australia during January 2011.

We have also examined observed fields of outgoing longwave radiation (OLR) and upper and lower tropospheric winds. We have found that Kelvin wave activity (not shown) in the period 10 to 15 January 2011 was a precursor to the flooding over north Australia. As well the tropical intraseasonal oscillation grew rapidly between 10 and 15 January 2011 (not shown), and maintained significant amplitude for the remainder of the month.

\section{DYNAMICAL MODES ASSOCIATED WITH LA NIÑA IN JANUARY 1974}

Just as the circulation in the Australia region has close similarities during January 2011 and January 1974, so do the properties of the classes of modes discussed in Section 4. Again, the leading storm track mode in southeastern Australia has a similar structure to mode 1 for 1949 - 1968 is shown in Figure 1 (top panel) of Frederiksen et al. (2011). The leading Kelvin wave (mode 17 with $T=15.6$ days, $\tau=3.3$ days) grows even more explosively than that for January 2011. It is structurally quite similar to that for the leading Kelvin wave for January 2011 shown in Figure 4. Again, in January 1974 there are fast growing intraseasonal oscillations (such as mode 45 with $T=55.9$ days, $\tau=5.3$ days) and monsoon disturbances (such as mode 62 with $T=\infty, \tau=6.4$ days) that are also consistent with the rainfall anomalies over Australia during the 1974 event.

\section{CONCLUSION}

Both 1974 and 2010-2011 La Niña conditions resulted in periods of extreme precipitation due to multiple strong climactic conditions converging on Australia at once, catalyzed by the large amounts of monsoonal moisture available in the atmosphere due to warmer SSTs from negative IOD conditions. An explosive Kelvin wave arrived over northern Australia at the right time to become convectively coupled in the Australian monsoon region, enhancing convection. At the same time, strong intraseasonal MJO moved through the region. Blocking high pressure systems in the Tasman Sea and unstable easterly winds associated with the low pressure served to prevent precipitation conditions from moving off the Australian coast. While the leading Kelvin wave and low pressure over Australia were stronger during the 1974 event than in January 2011, stronger negative IOD conditions in 2011 increased SSTs, leading to more moisture available in 2011 to be delivered as rainfall. We find that analyses of the dynamical modes are consistent with synoptic situation seen in observations. Determining the relative contributions of climate forcing versus internal variability is a next step in understanding these ENSO extreme events over Australia.

\section{ACKNOWLEDGEMENTS}

This publication is supported by the Australian Government Department of Industry, Innovation, Climate Change, Science, Research and Tertiary Education, the Bureau of Meteorology, and CSIRO through the Australian Climate Change Science Program. J. Whelan acknowledges the CSIRO office of the Chief Executive for funding her postdoctoral fellowship. We would also like to thank Matt Wheeler for his input and discussion on this work.

\section{REFERENCES}

Ashok, K., Z. Guan, and Yamagata, T. (2003). Influence of the Indian Ocean Dipole on the Australian winter rainfall. Geophys. Res. Lett., 30(15), 1821. DOI: 10.1029/2003GL017926.

Brown, J., Mcintosh, P.C., Pook, M.J, and Risbey, J.S. (2009). An investigation of the links between ENSO flavors and rainfall processes in southeastern Australia. Mon. Weather rev., 137,11, 3786-3795.

Cai, W., and Cowan, T. (2009). La Niña Modoki impacts Australia autumn rainfall variability. Geophys. Res. Lett., 36, L12805. DOI: 10.1029/2009GL037885.

Frederiksen, J.S. (1981). Scale selection and energy spectra of disturbances in Southern Hemisphere flows. $J$. Atmos. Sci., 38, 2573-2584.

Frederiksen, J.S. (2002). Genesis of intraseasonal oscillations and equatorial waves. J. Atmos. Sci., 59, 27612781. 
Whelan et al., Synoptic and dynamical analyses of ENSO extreme events over Australia

Frederiksen, J.S. and Frederiksen, C.S. (1993). Monsoon disturbances, intraseasonal oscillations, teleconnection patterns, blocking and storm tracks of the global atmosphere during January 1979: Linear theory. J. Atmos. Sci., 50, 1349-1372.

Frederiksen, J.S. and Frederiksen, C.S. (1997). Mechanisms of the formation of intraseasonal oscillations and Australian monsoon disturbances: The roles of convection, barotropic and baroclinic instability. Contrib. Atmos. Phys., 70, 39-56.

Frederiksen, J.S. and Frederiksen, C.S. (2005). Decadal changes in Southern Hemisphere winter cyclogenesis. CSIRO Marine and Atmospheric Research Paper No. 002, Aspendale, Vic.: CSIRO Marine and Atmospheric Research. V, 29p. http://www.cmar.csiro.au/e-print/open/frederiksenjs_2005b.pdf

Frederiksen, J.S. and Frederiksen, C.S. (2007). Interdecadal changes in southern hemisphere winter storm track modes, Tellus, 59A, 599-617.

Frederiksen, J.S., and Frederiksen, C.S. (2011). Twentieth century winter changes in Southern Hemisphere synoptic weather modes. Adv. Meteorol. Article ID 353829, 16pp, DOI:10.1155/2011/353829.

Frederiksen, J.S., Frederiksen, C.S., Osbrough, S.L. and Sisson, J.M. (2010). Causes of changing Southern Hemispheric weather systems, Chapter 8, Managing Climate Change, Eds. I. Jubb, P. Holper and W. Cai, CSIRO publishing, pp85-98.

Frederiksen, J.S., Frederiksen, C.S., Osbrough, S.L. and Sisson, J.M. (2011). Changes in Southern hemisphere rainfall, circulation and weather systems. In Chan, F., Marinova, D. and Anderssen, R.S. (eds) MODSIM2011, 19th International Congress on Modelling and Simulation. Modelling and Simulation Society of Australia and New Zealand, December 2011, pp. 2712-2718. ISBN: 978-0-9872143-1-7. www.mssanz.org.au/modsim2011/F5/frederiksen.pdf

Hendon H.H., Wheeler M.C., Zhang C. (2007). Seasonal dependence of the MJO-ENSO relationship. J. Climate, 20, 531-543.

Kalnay, E., et al. (1996). The NCEP/NCAR 40-year reanalysis project, Bull. Am. Meteorol. Soc., 3, 437-471.

McBride, J. L., and Nicholls, N. (1983). Seasonal relationships between Australian rainfall and the Southern Oscillation. Mon. Weather Rev., 111, 1998-2004.

Karoly, D.J. (1989). Southern Hemisphere circulation features associated with El Niño-Southern Oscillation events. J. Climate, 2, 1239-1252.

L'Heureux, M.L., and Thompson, D.W.J., (2006). Observed relationships between the El Niño-Southern Oscillation and the extratropical zonal-mean circulation. J. Climate, 19, 276-287.

Meyers, G., McIntosh, P., Pigot L., and Pook, M. (2007). The years of El Niño, La Niña, and interactions with the tropical Indian Ocean. J. Climate, 20, 2872-2880.

Moon, J-Y., Wang, B., and Ha, K-J. (2011). ENSO regulation of MJO teleconnection. Clim. Dynamics. 37.56, 1133-1149.

Nicholls, N., Drosdowsky, W., and Lavery, B. (1997). Australian rainfall variability and change. Weather, $52,66-71$.

Pezza, A. B., Durrant, T., Simmonds, I. and Smith I. (2008). Southern hemisphere synoptic behavior in extreme phases of SAM, ENSO, sea ice extent, and southern Australia rainfall. J. Climate, 21.21, 5566$5579,5581-5584$.

Philander, S. G., (1990). El Niño, La Niña, and the Southern Oscillation. Academic Press, 289 pp.

Risbey, J.S., Pook, M.J., McIntosh, P.C., Wheeler, M.C., Hendon, H.H. (2009). On the remote drivers of rainfall variability in Australia. Mon. Weather. Rev., 137, 3233-3253.

Taschetto, A. S., and England, M.H. (2009). El Niño Modoki impacts on Australian rainfall, J. Clim., 22 , 3167-3174.

Wang, G., and Hendon, H.H. (2007). Sensitivity of Australian rainfall to inter-El Niño variations. $J$. Climate, 20,4211-4226.

Wheeler, M.C., Hendon, H.H., Cleland, S., Meinke, H., Donald, A., (2009). Impacts of the Madden-Julian Oscillation on Australian rainfall and circulation. J. Climate, 22, 1482-1498. 